\title{
TIKTOK: BILANG MAKABAGONG PANDULOG AT ESTRATEHIYA SA PAGTUTURO NG ASIGNATURANG FILIPINO
}

\author{
Jasmine G. Cabanalan 1, Sierra Marie S. Aycardo, Ph.D. \\ ${ }^{1}$ Teacher II, Department of Education, Kabulusan Integrated National High School, Pakil, Laguna, \\ Phillipines. \\ ${ }^{2}$ Instructor 1, Commision on Higher Education, Laguna State Polytechnic University, Main Campus, \\ Santa Cruz, Laguna, Philippines.
}

Article DOI: https://doi.org/10.36713/epra7726

DOI No: 10.36713/epra7726

\begin{abstract}
ABSTRAK
Ang pag-aaral na ito ay may titulong "TIKTOK: BILANG MAKABAGONG PANDULOG AT ESTRATEHIYA SA PAGTUTURO NG ASIGNATURANG FILIPINO. Layunin ng pag-aaral na ito na mabatid ang kabisaan ng aplikasyong TikTok bilang makabagong pandulog at estratehiya sa pagtuturo ng asignaturang Filipino sa mga mag-aaral ng ikalabing-isang antas (11) sa Taong Panuruan 2020-2021.

Batay sa nakuhang datos, ang bisang pangkaisipan, bisang pandamdamin at aktibong pagkatuto ay kapwa lubhang matataas. Samakatuwid ang aplikasyong TikTok ay epektibo sa paglinang ng intelektwal na kasanayan, sariling pagpapahalaga, aktibong paglinang at paglalapat ng kaalamang natamo ng mga mag-aaral.

Ukol sa kinalabasan ng antas ng paunang pagsusulit ng mga mag-aaral, ito ay may markang medyo kasiyasiya habang ang panapos na pagsusulit naman ay nakakuha ng markang kasiya-siya. Nangangahulugan lamang ito na may makabuluhang pagkakaiba ng antas ng kanilang pagganap.

Ang haypotesis na walang makabuluhang pagkakaiba ang antas ng pagganap ng mga mag-aaral batay sa pauna at panapos na pagsusulit ay hindi tinanggap. Samakatuwid ay nagkaroon ng makabuluhang pagkakaiba sa mga nakuhang iskor ng mga mag-aaral.

Ang haypotesis na walang makabuluhang kaugnayan ang paggamit ng TikTok bilang makabagong pandulog at estratehiya sa pagtuturo ng asignaturang Filipino sa pagganap ng mga mag-aaral ay hindi tinanggap. Samakatuwid ay may makabuluhang kaugnayan sa pagitan nito. Ang paggamit nang nasabing pamamaraan sa tulong ng aplikasyong TikTok ay mabisa.

Dahil sa positibong kinalabasan ng pag-aaral, ang binuong mga bidyo sa pamamagitan ng aplikasyong TikTok ay maaaring gamitin bilang makabagong pandulog at estratehiya sa pagtuturo ng asignaturang Filipino. Ang mga guro ay hinihikayat na tumuklas pa ng mga makabagong estratehiya na maaaring maging lunsaran ng pagpapataas ng pagganap sa asignaturang Filipino. Malaki rin ang maitutulong ng mga teknik na ito sa mas madaling proseso ng pagkatuto at pagdaragdag ng kaalaman sa mga mag-aaral.
\end{abstract}

KEYWORDS: TikTok, pandulog at estratehiya sa pagtuturo, bisang pangkaisipan, bisang pandamdamin, bisa sa aktibong pagkatuto

\footnotetext{
2021 EPRA IJRD | Journal DOI: https://doi.org/10.36713/epra2016 | www.eprajournals.com |346 |
} 


\title{
EPRA International Journal of Research and Development (IJRD)
}

\author{
Volume: 6 | Issue: 7 | July 2021 \\ - Peer Reviewed Journal
}

\section{PANIMULA}

Ang bawat henerasyon ay may kani-kaniyang taglay na katangian na nagdudulot ng malaking epekto sa pamumuhay ng tao. Maraming pagbabago ang nangyayari sa larangan ng edukasyon, maging ang mga pamamaraan at estratehiya ng pagtuturo na nagsisilbing malaking hamon na kinahaharap ng mga guro. Ang pagpapanatili ng interes at motibasyon ng mga mag-aaral sa isang aralin ay isa sa mga pagsubok ng mga tagapagtaguyod ng edukasyon.

Ang mga binuong pamantayan sa pagsasaayos ng kurikulum para sa Edukasyon para sa Lahat 2015 (Education For All 2015) ay may pag-unawa sa nilalaman ng bawat asignatura katulad ng Filipino. Tinitiyak nito na ang mga dapat matutuhan at ang antas ng pagganap ng mag-aaral kaya mataas ang inaasahan nito. Ito ay mapanghamon kaya nararapat na gumagamit ng mga angkop na dulog at estratehiya upang malinang ang kaalaman at kakayahan ng mga mag-aaral upang maihanda sa paghahanapbuhay kung di man makapagpatuloy sa kolehiyo.

Ang modernong pagtuturo at teknolohikal na pagbabago sa ika-21 siglo ang pokus ng mga paaralan ngayon. Ito ay may ganap na pakinabang sa mga mag-aaral at guro. Mas pinalawak at mas pinalawig ang mga konsepto sapagkat nakikita ng mga mag-aaral ang nais ipahiwatig ng tiyak na paksa.

Ang paggamit ng mga maiikling bidyo ay isa sa mga pamamaraan na maiiugnay sa pagbabagong teknolohikal sa larangan ng edukasyon ngayon. Nagiging daan ito upang mapanatili ang interes ng mag-aaral sa aralin, napauunlad ang kakayahan sa pag-iisa at maaari ring maging batayan sa hinaharap. Kaugnay nito, sang-ayon sa artikulo ni Escober (2020) na ang aplikasyong TikTok ay nagiging daan ng mga kabataan upang matugunan ang simpleng realidad ng buhay at pagbuo ng mga makatotohanang kontent. Ang aplikasyong ito ay umusbong noong taong 2016, at naglalaman ng iba't ibang bidyo na patuloy na tinatangkilik nang karamihan.

Sa patuloy na pag-unlad ng bilang ng mga kabataang tumatangkilik ng aplikasyong TikTok, nagiging malaking bahagi na ito ng kanilang buhay. Dito nila mas naipakikita ang kanilang saloobin. Ito rin ang nagiging lunsaran nila upang makaangkop sa pagbabago sa kapaligiran. Kaya naman maaari itong makaimpluwensiya sa iba't ibang aspeto ng kanilang pamumuhay. Isa na rito ay ang larangan ng paglinang at pagkatuto na malaking salik sa kanila bilang isang indibidwal.

Sa ganitong kalagayan, ang pananaliksik na ito ay may naising mabatid ang kabisaan ng aplikasyong TikTok bilang makabagong pandulog at estratehiya sa pagtuturo ng asignaturang Filipino. Napili itong paksa ng mananaliksik sapagkat napapanahon ang pag-aaral dahil maraming mga mag-aaral ang tumatangkilik sa nasabing aplikasyon, at sa paglipas ng panahon ay maaaring mabago ang pamamaraan sa pagtuturo upang mapanatiling buhay at makabuluhan ang paglinang ng kaalaman ng mga mag-aaral.

\section{Layunin}

Ang pag-aaral na ito ay naglalayong matukoy ang kabisaan ng aplikasyong TikTok bilang makabagong pandulog at estratehiya sa pagtuturo ng asignaturang Filipino. Ang pag-aaral na ito ay nagnanais na alamin ang mga sumusunod na katanungan:

1. Ano ang antas ng paggamit ng TikTok bilang makabagong pandulog at estratehiya sa pagtuturo ng asignaturang Filipino batay sa:

\subsection{Bisang Pangkaisipan; \\ 1.2 Bisang Pandamdamin; at \\ 1.3 Bisa sa Aktibong Pagkatuto?}

2. Ano ang antas ng pagganap ng mga mag-aaral sa asignaturang Filipino batay sa paunang pagsusulit at panapos na pagsusulit?

3. May makabuluhang bang pagkakaiba ang antas ng pagganap ng mga mag-aaral batay sa pauna at panapos na pagsusulit?

4. May makabuluhang bang kaugnayan ang paggamit ng TikTok bilang makabagong pandulog at estratehiya sa pagtuturo ng asignaturang Filipino sa pagganap ng mga mag-aaral?

\section{METODOLOHIYA NG PANANALIKSIK Disenyo ng Pananaliksik}

Ang disenyong ginamit ng mananaliksik sa pag-aaral na ito ay eksperimental. Sang-ayon kay Tanner (2018) na ang eksperimental na pag-aaral ay may makabuluhang impluwensiya sa paghihinuha ng balidong resulta ng pag-aaral na isinasagawa. Ito rin ang ginamit sa pagsusog sa sanhi at bunga sa pagitan ng mga baryabol. 


\section{SJIF Impact Factor 2021: 8.013| ISI I.F.Value:1.241| Journal DOI: 10.36713/epra2016 \\ ISSN: 2455-7838(Online) \\ EPRA International Journal of Research and Development (IJRD)

\author{
Volume: 6 | Issue: 7 | July 2021
} \\ - Peer Reviewed Journal}

Sang-ayon din kay Ortiz (2015) na ang eksperimental na pananaliksik ay tunay na makasusubok sa palagay o haypotesis tungkol sa ugnayang sanhi at bunga. Kadalasan itong itinuturing na pinakasopistikadong pamamaraan ng pananaliksik para subukin ang mga palagay.

Ang pangunahing layunin ng pag-aaral na ito ay matukoy ang kabisaan ng paggamit ng aplikasyong TikTok bilang makabagong pandulog at estratehiya sa pagtuturo ng asignaturang Filipino sa mga mag-aaral na nasa ikalabing-isang (11) antas ng Kabulusan Integrated National High School.

\section{Tagatugon sa Pananaliksik}

Ang nagsilbing tagatugon sa pananaliksik na ito ay mga piling mag-aaral sa baitang labing-isa (11) ng Kabulusan Integrated National High School. Ang mga tagatugon ay limitado lamang sa limampung (50) mag-aaral na sumagot sa paunang pagsusulit, panapos na pagsusulit at talatanungan na ipinamahagi ng mananaliksik.

\section{Sampling Teknik}

Sa pagsasagawa ng pananaliksik na ito, ang mananaliksik ay gumamit ng "Purposive Sampling Technique". Sinasabing ito ang paraan ng pangangalap ng kinatawan na nakabase sa malalim na kaalaman at pagkilala ng mananaliksik sa populasyon. Sa pamamaraang ito ay direktang natutukoy ang kinatawan.

\section{Paraan ng Pananaliksik}

Ang mananaliksik ay may mga hakbang na isinagawa upang makakalap ng mga kinakailangang datos sa pag-aaral. Mula sa pagbabasa ng mga piling aklat sa sekundarya at mga piling pahina sa internet ay naging mapanuri ang mananaliksik sa pangangalap ng datos upang maging matagumpay at maging kapaki-pakinabang ang pag-aaral na ito.

Gumamit ang mananaliksik ng aplikasyong TikTok bilang makabagong pandulog at estratehiya sa pagtuturo ng asignaturang Filipino na kung saan isinangguni muna sa lupon ng pananaliksik upang magkaroon ito ng balidasyon. Pagkatapos ng balidasyon, ipinagamit sa mga tagatugon ng pag-aaral upang malaman ang kabisaan nito sa pagkatuto ng mga mag-aaral.

Ang ginamit na instrumento sa pananaliksik ay talatanungan, paunang pagsusulit at panapos na pagsusulit. Sa pagbuo ng talatanungan sa pananaliksik na ito, ang mananaliksik ay bumatay sa mga kasanayang pagkatuto na kaugnay at dapat matamo ng mga mag-aaral sa asignaturang Filipino ng ikalabing-isang antas. Ang talatanungang ito ay nagsilbing survey questionnaire patungkol sa antas ng kabisaan ng aplikasyon TikTok batay sa bisang pangkaisipan, bisang pandamdamin at bisa sa aktibong pagkatuto. Ito ay mayroong kabuuang tatlumpung (30) pahayag; at ang pauna at panapos na pagsusulit naman ay ang pagtataya na susukat sa kaalamang natamo ng mga mag-aaral na binubuo ng tatlumpung (30) aytem.

\section{Instrumento ng Pananaliksik}

Ang mananaliksik ay bumuo ng mga bidyo na naglalaman ng mga aralin na kaugnay ng asignaturang Filipino gamit ang aplikasyong Tiktok bilang makabagong pandulog at estratehiya sa pagtuturo ng nasabing asignatura. Ang ginawang talatanungan ng mananaliksik ay ginamit bilang instrumento sa pagkalap ng mga kinakailangang datos. Layunin ng talatanungan na makagawa ng pagtataya sa mga tagatugong mag-aaral.

Ang nilalaman ng talatanungan ay sinagutan ng mga mag-aaral. Ang bigat ng karampatang puntos sa kasagutan sa bahaging ito ay ang mga sumusunod:

$4.50-5.00 \quad$ Lubos na Sumasang-ayon (LS)

3. $51-4.50 \quad$ Sumasang-ayon (S)

2. $51-3.50 \quad$ Katamtamang Sumasang-ayon (KS)

$1.51-2.50 \quad \mathrm{Di}-$ Sumasang-ayon (DS)

$1.00-1.50 \quad$ Lubos na Di- Sumasang-ayon (LDS)

Bumuo rin ng paunang pagsusulit at panapos na pagsusulit na sumukat sa kaalamang natamo ng mga magaaral matapos mapanood ang mga bidyo sa pamamagitan ng aplikasyong TikTok bilang makabagong pandulog at estratehiya sa pagtuturo ng asignaturang Filipino.

\section{Istatistikal na Pamamaraan}

Gumamit ang mananaliksik ng mga pamamaraang istadistika upang mabigyan nang angkop at malinaw na pagsusuri, pagtataya at interpretasyon ang mga nalikom na datos. 


\title{
SJIF Impact Factor 2021: 8.013| ISI I.F.Value:1.241| Journal DOI: 10.36713/epra2016 ISSN: 2455-7838(Online) EPRA International Journal of Research and Development (IJRD)
}

\author{
Volume: 6 | Issue: 7 | July 2021
}

- Peer Reviewed Journal

Sa pagtukoy sa resulta ng antas ng paggamit ng TikTok bilang makabagong pandulog at estratehiya sa pagtuturo ng asignaturang Filipino batay sa bisang pangkaisipan, bisang pandamdamin at bisa sa aktibong pagkatuto, gumamit ang mananaliksik ng weighted mean at standard deviation ang mananaliksik.

Sa antas naman ng pagganap ng mga mag-aaral sa asignaturang Filipino batay sa paunang pagsusulit at panapos na pagsusulit, gumamit din ng weighted mean at standard deviation.

Upang masukat kung mayroon bang makabuluhang pagkakaiba ang antas ng pagganap ng mga mag-aaral batay sa paunang pagsusulit at panapos na pagsusulit, ginamit ang Mean at T-test.

Samantalang upang malaman kung mayroon bang makabuluhang relasyon ang paggamit ng TikTok bilang makabagong pandulog at estratehiya sa pagtuturo ng asignaturang Filipino sa pagganap ng mga mag-aaral, gumamit ang mananaliksik ng $r$-value at $p$-value.

\section{KINALABASAN, MUNGKAHI, AT KONKLUSYON \\ Kinalabasan}

Layunin ng pag-aaral na mabatid ang kabisaan ng aplikasyong TikTok bilang makabagong pandulog at estratehiya sa pagtuturo ng asignaturang Filipino sa piling mga mag-aaral ng ikalabing-isang (11) antas ng Kabulusan Integrated National High School sa taong-panuruan 2019-2020.

Batay sa mga datos na nakalap mula sa mga piling mag-aaral ng ikalabing-isang (11) antas ng Kabulusan Integrated National High School. Lumabas sa resulta ng antas ng paggamit ng TikTok bilang makabagong pandulog at estratehiya sa pagtuturo ng asignaturang Filipino batay sa bisang pangkaisipan ay may puna na lubos na sumasang-ayon at literal na paliwanag na lubhang mataas.

Batay sa resulta, ang antas ng paggamit ng TikTok bilang makabagong pandulog at estratehiya sa pagtuturo ng asignaturang Filipino batay sa bisang pandamdamin ay may puna na lubos na sumasang-ayon at literal na paliwanag na lubhang mataas.

Lumabas sa resulta ng antas ng paggamit ng TikTok bilang makabagong pandulog at estratehiya sa pagtuturo ng asignaturang Filipino batay sa bisa sa aktibong pagkatuto ay may puna na lubos na sumasang-ayon at literal na paliwanag na lubhang mataas.

Ang antas ng pagganap ng mga mag-aaral sa asignaturang Filipino batay sa paunang pagsusulit ay may literal na paliwanag na Katamtamang Mahusay. Samantalang ang antas ng pagganap ng mga mag-aaral sa asignaturang Filipino batay sa panapos na pagsusulit naman ay may literal na paliwanag na Mahusay.

Batay sa resulta, ipinapakita na may makabuluhang pagkakaiba ang ang antas ng pagganap ng mga magaaral batay sa pauna at panapos na pagsusulit. Kaya naman ang walang bisang palagay na "Walang makabuluhang pagkakaiba ang antas ng pagganap ng mga mag-aaral batay sa pauna at panapos na pagsusulit" ay hindi tinanggap.

Sang-ayon sa resulta, may makabuluhang kaugnayan ng paggamit ng TikTok bilang makabagong pandulog at estratehiya sa pagtuturo ng asignaturang Filipino sa pagganap ng mga mag-aaral. At batay rin dito, ang walang bisang palagay na "Walang makabuluhang kaugnayan ng paggamit ng TikTok bilang makabagong pandulog at estratehiya sa pagtuturo ng

asignaturang Filipino sa pagganap ng mga mag-aaral" ay hindi tinanggap.

\section{Mungkahi}

Matapos ang pag-aaral at pagsusuri ng mga natuklasan, iminumungkahi ng mananaliksik ang sumusunod na rekomendasyon.

1. Bukod sa bisang pangkaisipan, bisang pandamdamin at aktibong pagkatuto, maaari pang tumuklas ang mga guro ng iba pang aspeto na pagtutuunan ng pansin sa pagtukoy ng kabisaan ng isang estratehiya sa pagtuturo upang mapataas ang antas ng edukasyon.

2. Dahil sa positibong kinalabasan ng pag-aaral, ang binuong mga bidyo ay maaaring gamitin bilang makabagong pandulog at estratehiya sa pagtuturo ng asignaturang Filipino sa ikalabing-isang (11) antas.

3. Ang mga guro ay hinihikayat na tumuklas pa ng mga makabagong estratehiya katulad ng paggamit ng TikTok na kinahihiligan ng mga mag-aaral sa kasalukuyan na maaaring maging lunsaran ng pagpapataas ng pagganap sa asignaturang Filipino. Malaki rin ang maitutulong ng mga teknik na ito sa mas madaling proseso ng pagkatuto at pagdaragdag ng kaalaman sa mga mag-aaral. 


\title{
EPRA International Journal of Research and Development (IJRD)
}

\author{
Volume: 6 | Issue: 7 | July 2021
}

- Peer Reviewed Journal

\section{Konklusyon}

Sa pamamagitan ng mga inilahad na kinalabasan, nabuo ang mga sumusunod na konklusyon.

1. Ang walang bisang haypotesis na walang makabuluhang pagkakaiba ang antas ng pagganap ng mga mag-aaral batay sa pauna at panapos na pagsusulit ay hindi tinanggap. Samakatuwid ay nagkaroon ng makabuluhang pagkakaiba sa mga nakuhang iskor ng mga mag-aaral, at ang kinalabasang ito ay nangangahulugang naging mabisa ang TikTok bilang makabagong pandulog at estratehiya sa pagtuturo ng asignaturang Filipino.

2. Ang walang bisang haypotesis na walang makabuluhang kaugnayan ang paggamit ng TikTok bilang makabagong pandulog at estratehiya sa pagtuturo ng asignaturang Filipino sa pagganap ng mga mag-aaral ay hindi tinanggap. Samakatuwid ay may makabuluhang kaugnayan sa pagitan nito. Nangangahulugan ito na mahalaga ang paggamit ng TikTok bilang makabagong pandulog at estratehiya sa pagtuturo. Ang paggamit nang nasabing pamamaraan sa tulong ng aplikasyong TikTok ay mabisa.

\section{MGA TALAHANAYAN}

Talahanayan 1. Antas ng paggamit ng TikTok bilang makabagong pandulog at estratehiya sa pagtuturo ng asignaturang Filipino batay sa Bisang Pangkaisipan

\begin{tabular}{|c|c|c|c|}
\hline Mga Pahayag & Mean & SD & Puna \\
\hline $\begin{array}{l}\text { Nakatutulong sa pagpapataas ng antas ng kaalaman at natutunang } \\
\text { kompetensi. }\end{array}$ & 4.56 & 0.67 & Lubos na sumasang-ayon \\
\hline $\begin{array}{l}\text { Madaling naipoproseso ang mga itinuturong aralin sa asignaturang } \\
\text { Filipino. }\end{array}$ & 4.56 & 0.58 & Lubos na sumasang-ayon \\
\hline $\begin{array}{l}\text { Mas natatandaan ang mga makabuluhang kahulugan, katuturan at } \\
\text { ideya ng paksa. }\end{array}$ & 4.50 & 0.61 & Lubos na sumasang-ayon \\
\hline $\begin{array}{l}\text { Madaling nagagamit ang aplikasyong TikTok sa pagtugon sa } \\
\text { pangangailangan ng mga mag-aaral kaugnay sa pag-unawa ng iba't } \\
\text { bang teksto. }\end{array}$ & 4.46 & 0.79 & Lubos na sumasang-ayon \\
\hline $\begin{array}{l}\text { Nakatutulong upang maisalin ang bagong kaalaman o kasanayan sa } \\
\text { tunay na sitwasyon ng buhay. }\end{array}$ & 4.40 & 0.73 & Lubos na sumasang-ayon \\
\hline $\begin{array}{l}\text { Nalilinang ang pagpapaunlad ng kritikal na pag-iisip at malikhaing } \\
\text { pagsasanay. }\end{array}$ & 4.46 & 0.71 & Lubos na sumasang-ayon \\
\hline Mas napagtitibay ang pag-aanalisa sa paksa. & 4.40 & 0.67 & Lubos na sumasang-ayon \\
\hline $\begin{array}{l}\text { Nakapagpapalawak ng imahinasyon habang pinanonood ang bidyo } \\
\text { na kaugnay ng paksa. }\end{array}$ & 4.52 & 0.58 & Lubos na sumasang-ayon \\
\hline $\begin{array}{l}\text { Mas mabilis maiugnay ang dati nang kaalaman sa panibagong } \\
\text { impormasyon. }\end{array}$ & 4.58 & 0.57 & Lubos na sumasang-ayon \\
\hline Nagdudulot ng makabuluhang ebalwasyon patungkol sa paksa. & 4.46 & 0.65 & Lubos na sumasang-ayon \\
\hline \multicolumn{4}{|l|}{$\begin{array}{l}\text { Overall Mean: } 4.49 \\
\text { Standard Deviation: } 0.656 \\
\text { Literal na paliwanag: } \text { Lubhang Mataas }\end{array}$} \\
\hline \multicolumn{4}{|l|}{ Palatandaan } \\
\hline Sukatan Saklaw & \\
\hline Lubos na sumasang-ayon Lubhan & \multicolumn{3}{|c|}{$\begin{array}{l}\text { Literal na paliwanag } \\
\text { Lubhang mataas }\end{array}$} \\
\hline Higit na karaniwang sumasang-ayon & \multicolumn{3}{|l|}{ Mataas } \\
\hline Sumasang-ayon & \multicolumn{3}{|c|}{ Medyo mataas } \\
\hline Hindi gaanong sumasang-ayon & \multicolumn{3}{|c|}{ Mababa } \\
\hline Lubos na Hindi Sumasang-ayon & \multicolumn{3}{|c|}{ Lubhang mababa } \\
\hline
\end{tabular}




\title{
EPRA International Journal of Research and Development (IJRD)
}

\author{
Volume: 6 | Issue: 7 | July 2021
}

- Peer Reviewed Journal

Talahanayan 2. Antas ng paggamit ng TikTok bilang makabagong pandulog at estratehiya sa pagtuturo ng asignaturang Filipino batay sa Bisang Pandamdamin

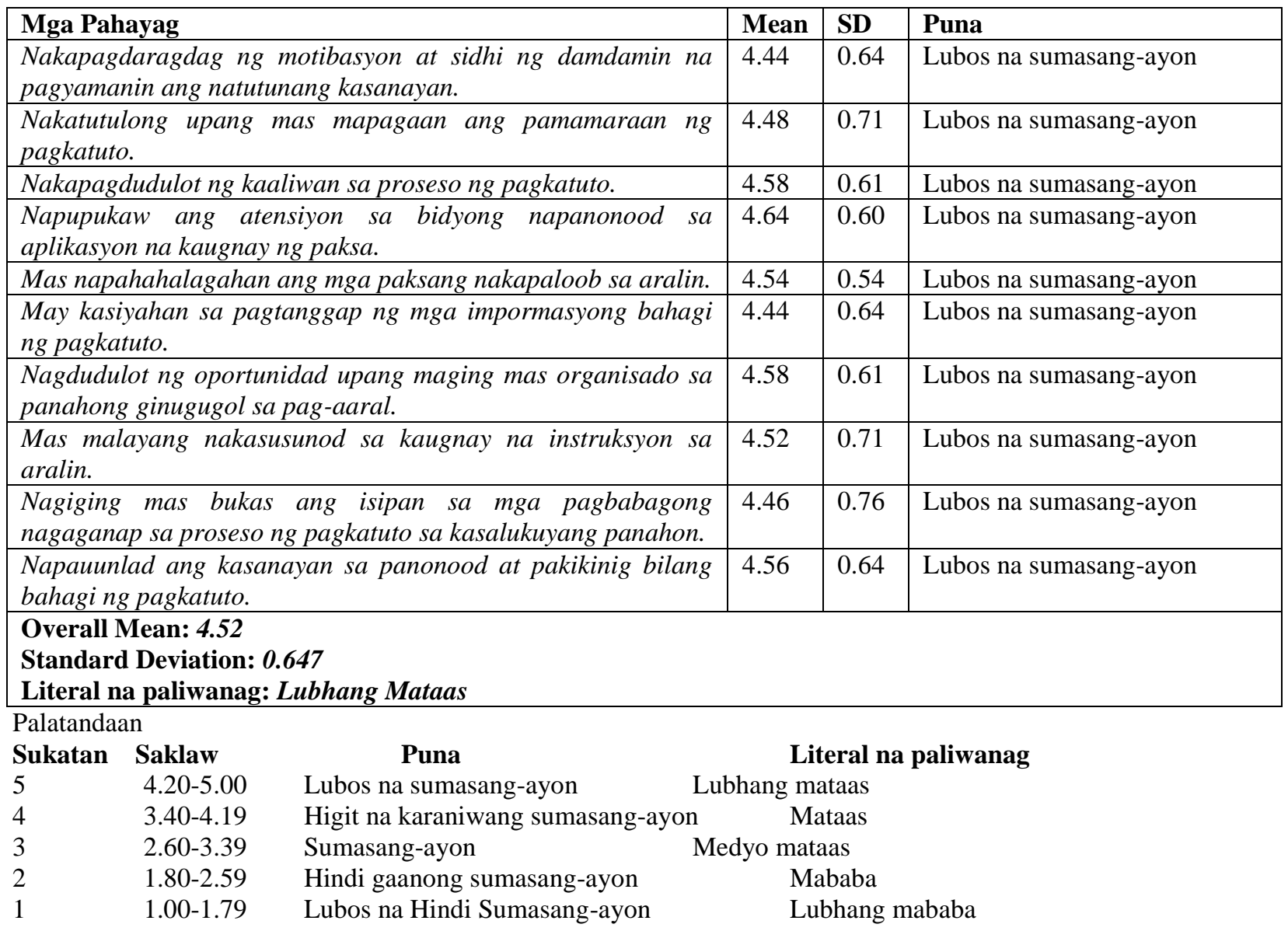

Talahanayan 3. Antas ng paggamit ng TikTok bilang makabagong pandulog at estratehiya sa pagtuturo ng asignaturang Filipino batay sa Bisa sa Aktibong Pagkatuto

\begin{tabular}{|l|l|l|l|}
\hline Mga Pahayag & Mean & SD & Puna \\
\hline Napahuhusay ang mga natamong kompetensi. & 4.52 & 0.65 & Lubos na sumasang-ayon \\
\hline Napauunlad ang kakayahan sa malayang pagkatuto. & 4.48 & 0.68 & Lubos na sumasang-ayon \\
\hline $\begin{array}{l}\text { Agarang nakatutugon at nakabubuo ng kasagutan sa mga pagtataya } \\
\text { at ebalwasyon. }\end{array}$ & 4.50 & 0.61 & Lubos na sumasang-ayon \\
\hline $\begin{array}{l}\text { Napauunlad ang kasanayan sa pagsulat sa pamamagitan ng mga } \\
\text { bidyong kaugnay ng aralin. }\end{array}$ & 4.44 & 0.67 & Lubos na sumasang-ayon \\
\hline $\begin{array}{l}\text { Mas napadadali ang pagsusuri ng iba't ibang teksto tungo sa } \\
\text { pananaliksik. }\end{array}$ & 4.52 & 0.68 & Lubos na sumasang-ayon \\
\hline $\begin{array}{l}\text { Mas nailalapat ang mga natamong kaalaman mula sa aralin sa } \\
\text { realidad ng buhay. }\end{array}$ & 4.42 & 0.67 & Lubos na sumasang-ayon \\
\hline $\begin{array}{l}\text { Napauunlad ang integrasyon ng teknolohiya at aralin tungo sa mas } \\
\text { mabilis na pagkaunawa sa paksa. }\end{array}$ & 4.60 & 0.67 & Lubos na sumasang-ayon \\
\hline $\begin{array}{l}\text { Nakabubuo ng makabuluhang repleksyon o pagninilay patungkol sa } \\
\text { aralin pagkatapos manood ng bidyo. }\end{array}$ & 4.54 & 0.65 & Lubos na sumasang-ayon \\
\hline $\begin{array}{l}\text { Nalilinang ang eksperimental at praktikal na pagsasanay na } \\
\text { kaugnay ng aralin. }\end{array}$ & 4.54 & 0.61 & Lubos na sumasang-ayon \\
\hline
\end{tabular}




\title{
EPRA International Journal of Research and Development (IJRD)
}

\author{
Volume: 6 | Issue: 7 | July 2021
}

- Peer Reviewed Journal

Nakapagdudulot ng oportunidad upang mas mapayabong ang
kakayahang makapagbahagi ng natamong kaalaman sa kapwa mag-
aaral.

Palatandaan

\begin{tabular}{lclc} 
Sukatan & Saklaw & \multicolumn{1}{c}{ Puna } & \multicolumn{2}{c}{ Literal na paliwanag } \\
5 & $4.20-5.00$ & Lubos na sumasang-ayon & Lubhang mataas \\
4 & $3.40-4.19$ & Higit na karaniwang sumasang-ayon & Mataas \\
3 & $2.60-3.39$ & Sumasang-ayon & Medyo mataas \\
2 & $1.80-2.59$ & Hindi gaanong sumasang-ayon & Mababa \\
1 & $1.00-1.79$ & Lubos na Hindi Sumasang-ayon & Lubhang mababa
\end{tabular}

Talahanayan 4. Antas ng pagganap ng mga mag-aaral sa asignaturang Filipino batay sa paunang pagsusulit

\begin{tabular}{|l|l|l|l|}
\hline Marka & Kabuuan & Bahagdan & Literal na Paliwanag \\
\hline $29-30$ & 0 & 0.00 & Pinakamahusay \\
\hline $26-28$ & 1 & 2.00 & Higit na Mahusay \\
\hline $20-25$ & 19 & 38.00 & Mahusay \\
\hline $17-19$ & 17 & 34.00 & Katamtamang Mahusay \\
\hline $5-16$ & 13 & 26.00 & Di -Gaanong Mahusay \\
\hline $2-4$ & 0 & 0.00 & Di -Lubhang Mahusay \\
\hline $0-1$ & 0 & 0.00 & Di- Mahusay \\
\cline { 1 - 2 } Total & $\mathbf{5 0}$ & $\mathbf{1 0 0}$ & \multirow{2}{*}{ Katamtamang Mahusay } \\
\cline { 1 - 2 } $\begin{array}{l}\text { Weighted Mean } \\
\text { Markamababang }\end{array}$ & $\mathbf{1 9 . 1 8}$ & \\
\cline { 1 - 2 } $\begin{array}{l}\text { Pinakamataas } \\
\text { marka }\end{array}$ & $\mathbf{2 6}$ & \\
\cline { 1 - 2 } \begin{tabular}{l} 
Standard Deviation \\
\cline { 1 - 2 }
\end{tabular} & $\mathbf{3 . 9 2 1}$ & \\
\hline
\end{tabular}

Palatandaan:

Sukatan

$96 \%-100 \%$

$86 \%-95 \%$

$66 \%-85 \%$

$55 \%-65 \%$

$15 \%-54 \%$

$5 \%-14 \%$

$0-4 \%$
Literal na Paliwanag

Pinakamahusay

Higit na Mahusay

Mahusay

Katamtamang Mahusay

Di -Gaanong Mahusay

Di -Lubhang Mahusay

Di- Mahusay 


\section{EPRA International Journal of Research and Development (IJRD)}

Talahanayan 5. Antas ng pagganap ng mga mag-aaral sa asignaturang Filipino batay sa panapos pagsusulit

\begin{tabular}{|c|c|c|c|}
\hline Marka & Kabuuan & Bahagdan & Literal na Paliwanag \\
\hline $29-30$ & 1 & 2.00 & Pinakamahusay \\
\hline $26-28$ & 11 & 22.00 & Higit na Mahusay \\
\hline $20-25$ & 28 & 56.00 & Mahusay \\
\hline $17-19$ & 7 & 14.00 & Katamtamang Mahusay \\
\hline $5-16$ & 3 & 6.00 & Di -Gaanong Mahusay \\
\hline $2-4$ & 0 & 0.00 & Di -Lubhang Mahusay \\
\hline $0-1$ & 0 & 0.00 & Di- Mahusay \\
\hline Total & 50 & 100 & \multirow{5}{*}{ Mahusay } \\
\hline Weighted Mean & \multicolumn{2}{|l|}{22.58} & \\
\hline $\begin{array}{l}\text { Pinakamababang } \\
\text { Marka }\end{array}$ & \multicolumn{2}{|l|}{12} & \\
\hline $\begin{array}{l}\text { Pinakamataasna } \\
\text { marka }\end{array}$ & \multicolumn{2}{|l|}{29} & \\
\hline Standard Deviation & \multicolumn{2}{|l|}{3.581} & \\
\hline
\end{tabular}

Palatandaan:

\section{Sukatan}

$96 \%-100 \%$

$86 \%-95 \%$

$66 \%-85 \%$

$55 \%-65 \%$

$15 \%-54 \%$

$5 \%-14 \%$

$0-4 \%$
Literal na Paliwanag

Pinakamahusay

Higit na Mahusay

Mahusay

Katamtamang Mahusay

Di -Gaanong Mahusay

Di -Lubhang Mahusay

Di- Mahusay

Talahanayan 6. Makabuluhang pagkakaiba ng antas ng pagganap ng mga mag-aaral batay sa pauna at panapos na pagsusulit

\begin{tabular}{|l|l|l|l|l|l|}
\hline Pagsusulit & Mean & $\begin{array}{l}\text { Computed t- } \\
\text { value }\end{array}$ & $\begin{array}{l}\text { Critical } \\
\text { t-value }\end{array}$ & p-value & Analysis \\
\hline Pauna & 19.18 & 4.5947 & 1.6609 & 0.0000 & Makabuluhan \\
\hline Panapos & 22.58 & & & \\
\hline
\end{tabular}

Talahanayan 7. Makabuluhang kaugnayan ng paggamit ng TikTok bilang makabagong pandulog at estratehiya sa pagtuturo ng asignaturang Filipino sa pagganap ng mga mag-aaral

\begin{tabular}{|l|l|c|c|c|}
\hline Estratehiya sa pagtuturo & Kaugnayan & r-value & Katibayan ng Ugnayan & Analisis \\
\hline Bisang Pangkaisipan & \multirow{5}{*}{ Bisang Pandamdamin } & 0.1957 & Napakababang pagkakaugnay & Makabuluhan \\
\cline { 1 - 3 } & & 0.2531 & Mababang pagkakaugnay & Makabuluhan \\
\cline { 1 - 3 } Bisa sa Aktibong Pagkatuto & \multirow{3}{*}{ Pagganap } & 0.1557 & Napakababang pagkakaugnay & Makabuluhan \\
& & & & \\
\hline
\end{tabular}




\title{
EPRA International Journal of Research and Development (IJRD)
}

\author{
Volume: 6 | Issue: 7 | July 2021
}

Palatandaan:
Sukatan
Katibayan ng Ugnayan
$\pm 0.00$
Walang Pagkakaugnay, Walang Relasyon
$\pm 0.01- \pm 0.20$ Napakababang Pagkakaugnay, Halos Walang Relasyon
$\pm 0.21- \pm 0.40$ Mababang Pagkakaugnay, Tiyak ngunit Mababaw ang Relasyon
$\pm 0.41- \pm 0.70$ Katamtamang Pagkakaugnay, Makabuluhan ang Relasyon
$\pm 0.71- \pm 0.90$ Mataas na Pagkakaugnay, Kapuna-Puna ang Relasyon
$\pm 0.91- \pm 0.99$ Napakataas na Pagkakaugnay, Mapapaniwalaan ang Relasyon
$\pm 1.00$
Lubos ang Pagkakaugnay, Ganap na May Relasyon

\section{TALASANGGUNIAN}

A. Mga Aklat

1. Acopra, J., Catipon, L., Lazaro N, \& Enrile A (2016). “Akademikong Filipino sa Piling Larangan. ”MIndshapers CO., INC. Intramuros Manila, p. 110

2. Badayos, P. (2012)" Metodolohiya sa Pagtuturo ng Wika (Mga Teorya, Simulain at Estratehiya)" .Grandbook Publishing House Inc.

3. Dron, H. \& Anderson, T. (2014) "Teaching Crowds: Learning and Social Media”. Athabasca University Press

4. Fenol, R. (2016). "Bata, Bata, Paano Ka Matututo? Isang Pagsusuri tungkol sa Estilong Pagkatuto ng mga Mag-aaral sa Ika-anim na Baitang sa Paaralang Elementarya ng Kaytitinga”, p.p:38-51

5. Roehl, A., Reddy S., Shannon, G. (2013) "The Flipped Classroom: AnOpportunity To Engage Millennial Students Through Active Learning Strategies"

6. Ruiz, F. A. (2017) "Kalatas Opisyal na Pahayagan ng Pambansang Samahanng mga Tagamasid at Tagapagturo sa Filipino"

B. Mga Tesis

1. Aguilor, D. O. (2020) "Paggamit ng Wikabulary Game sa Pagpapaunlad ng Talasalitaan ng mga Mag-aaral"

2. Magnaye, M. H. (2016) "Epekto ng Paggamit ng Iba’t Ibang Estratehiya sa Pagtuturo ng Asignaturang Filipino sa Pagkatuto ng mga Mag-aaral"

3. Rojas, M.T. (2015) "Kaugnayan ng Pangkatang Gawain sa Pagkatuto ng mga Mag-aaral sa Pagkatuto ng mga Mag-aaral sa Asignaturang Filipino.General Licerio Geronimo National High School. Division of Calamba City”

\section{Elektronikong Hanguan}

1. Dilon, C. (2020) TikTok Influences on Teenagers and Young Adult $s$ Students: The Common Usages of the Application. Vol 0, pp. 132-142.Retrievedfrom https://www.researchgate.net/publication/341616421

2. Escober, E. (2020) How TikTok Became the Pasttime of a Country in Quarantine. CNN Philippines Life Manila. Retrieved from cnn.ph/life/culture/tech/2020/3/30/tiktok-pandemic-content.html

3. Ortiz, A. (2015) Sulating Pananaliksik1. Retrieved from https://www.slideshare.net/allanortiz/sulating-pananaliksik154345324

4. Tanner, K. (2018) Research Methods (Second Edition). Retrieved from sciencedirect.com/topics/socialsciences/experimental-research 